\title{
SCHOOLS IN THE SHADOW OF TERRORISM: PSYCHOSOCIAL ADJUSTMENT AND INTEREST IN INTERVENTIONS FOLLOWING TERROR ATTACKS
}

\author{
ERIKA FELIX \\ Gevirtz Graduate School of Education, University of California, Santa Barbara \\ ERIC M. VERNBERG \\ Clinical Child Psychology Program, University of Kansas, Lawrence \\ ROSE L. PFEFFERBAUM \\ Liberal Arts Department, Phoenix College, Phoenix \\ DODIE C. GILL \\ New Millennium Employees Assistance Services, LLC \\ JOHN SCHORR \\ Department of Sociology, Stetson University, DeLand \\ ANGELA BOUDREAUX \\ Halifax Medical Center, Daytona Beach \\ ROBIN H. GURWITCH \\ Division of Developmental and Behavioral Pediatrics, National Center for School Crisis and Bereavement, Cincinnati \\ SANDRO GALEA \\ Department of Epidemiology, University of Michigan School of Public Health, Ann Arbor \\ BETTY PFEFFERBAUM \\ College of Medicine, University of Oklahoma Health Sciences Center, Oklahoma City
}

\begin{abstract}
Following terrorist events, teachers and nonteaching school personnel are important in helping children recover, yet little is known about their willingness to assist with this. We surveyed 399 employees from a Washington, D.C.-area school district following terror attacks (September 11, 2001, attacks; sniper shootings) about their exposure, adjustment, interest, and involvement in psychosocial interventions. Between $10 \%$ and $27 \%$ experienced one or more symptoms of posttraumatic stress (depending on category of symptom) in the month prior to the survey. Regression analyses revealed that peritraumatic distress, behavior change, and posttraumatic growth predicted interest in information on psychosocial interventions. Feeling prepared, adaptively managing work responsibilities, and perceiving an increase in student problems were related to intervening with students. Implications for school preparedness are discussed. (C) 2010 Wiley Periodicals, Inc.
\end{abstract}

Teachers and nonteaching school personnel (e.g., counselors, psychologists, speech therapists, administrators, support staff) are on the front lines of helping students cope with and recover from community- or schoolwide traumatic events, whether they are prepared for this role or not. Both the Oklahoma City bombing and the September 11, 2001, terrorist attacks occurred on a weekday during school hours within the academic year; consequently, most school-age children and adolescents in communities near the attack sites were in school at the time of the events. When schools are near terrorist attack sites, teachers and school personnel must manage their own personal needs and respond to student needs as events unfold and during recovery (Greene, Barrios, Blair, \& Kolbe, 2004). They may have immediate responsibility for the welfare of students and for re-establishing a sense of safety in the near aftermath of these horrific events. Following the Oklahoma City bombing,

Correspondence to: Erika Felix, Gevirtz Graduate School of Education, University of California, Santa Barbara, Santa Barbara, CA 93106-9490. E-mail: efelix@education.ucsb.edu 
most bomb-related services for children were delivered through the schools (Pfefferbaum et al., 2003).

\section{Mental Health Impact of Terrorism}

After terror attacks or natural disasters, many survivors show transient symptoms of distress, sadness, and anxiety, which may resolve on their own (Norris, Friedman, Watson, \& Byrne, 2002). A significant minority, however, experience reactions that meet criteria for a psychiatric disorder. In a study of the mental health reactions of a representative sample of adults in New York City following the September 11, 2001, terror attacks, Galea and colleagues (2002) found that $7.5 \%$ reported symptoms consistent with a diagnosis of posttraumatic stress disorder (PTSD) related to the attacks, and $9.7 \%$ reported symptoms of a depressive disorder. The closer the respondents lived to the World Trade Center (WTC), the higher the rates of PTSD (20.0\%). Even a year after the September 11, 2001, terror attacks in New York City, Adams and Boscarino (2005) found that the greater the exposure, the poorer the person's mental health, even after taking into account demographics, other stressors, and social and psychological resources.

For teachers specifically, prior research has shown that they reported difficulty in their professional role performance in terms of managing their own reactions or in addressing the needs of students or parents in the months following terrorist attacks (B. Pfefferbaum et al., 2004; R.L. Pfefferbaum et al., 2004). In a case study of one New York City school following the September 11,2001 , terror attacks, a significant minority of teachers reported 9-12 months after the attacks that the events continued to make them upset at home and/or work, they found it harder to pay attention at work, and they had difficulty relaxing at home some of the time (R.L. Pfefferbaum et al., 2004). In a convenience sample of 894 teachers surveyed approximately 7 weeks after the Oklahoma City bombing, struggles with role performance were related to stronger peritraumatic reactions (e.g., emotional reactions related to exposure to the traumatic event), ongoing worry about personal safety, posttraumatic stress symptoms (PTSS), and stress related to responding to the postbombing reactions of students (B. Pfefferbaum et al., 2004).

\section{Factors Affecting Distress}

There are potential individual characteristics that influence emotional reactions to trauma. One potential pathway between a traumatic event and recovery is the individual's coping self-efficacy or perceived capability to manage one's reactions and continue functioning posttrauma (Benight \& Bandura, 2004). For teachers and nonteaching school personnel, higher coping self-efficacy may translate into being better prepared to help students as they deal with the aftermath of a traumatic event. In a study of occupational stress and burnout of teachers, Mearns and Cain (2003) found that coping style and negative mood regulation expectancies, which involve the perceived ability to successfully manage negative emotions, affected teacher distress. The ability of teaching and nonteaching school personnel to successfully manage their emotional reactions as a terror or crisis event unfolds has an important relation to students' psychological reactions. A review of research has shown that the more children perceive their lives, or the lives of loved ones to be threatened, the higher the rate of subsequent PTSD symptoms (Silverman \& La Greca, 2002). Thus, when a crisis event occurs at school, children will look at the reactions of the adults present to gauge their own level of safety.

\section{The Potential Role of School Personnel in Children's Recovery}

Wolmer, Laor, and Yazgan (2003) make a case for teachers to serve as clinical mediators in providing psychosocial recovery interventions to students postdisaster. They argue that, although 
under routine conditions or small events, school psychologists and counselors are the first-choice professionals for emergency response, the very nature of a wide-scale disaster can preclude this. In these situations, school counselors and psychologists can take a training and supervisory role and allow teachers to be clinical mediators. Thus, teachers can be a resource to provide classroom-based socioemotional recovery efforts. They suggest that teachers occupy this role because they play a central part within the lives of children, they are viewed as trustworthy by students and parents, and many are amenable to being trained for a more therapeutic role (Wolmer, Laor, Dedeoglu, Siev, \& Yazgan, 2005). In a study of a teacher-provided intervention with child survivors of an earthquake in Turkey, the rate of recovery over a 3-year period was faster for intervention students than for control students (Wolmer et al., 2005). This finding suggests that teachers can be used to lessen the long-term suffering of students.

Indeed, Wolmer and associates (2003) emphasize that classroom-based programs that focus on socioemotional recovery implemented in schools may benefit from the existing, supportive relationships students and teachers have. They argue that support from classmates and teachers can reduce PTSS after a traumatic event, and note that many schools already deliver preventive interventions for other psychosocial issues, such as violence prevention and socioemotional competence. Finally, they argue that the classroom provides a predictable routine, clear expectations, consistent rules, and immediate feedback that can benefit program implementation.

Teachers and nonteaching school personnel are important agents of recovery for children following disasters, yet little research has examined how they have fared in meeting this expectation. It remains unclear how personal distress of teachers and staff is related to their interest and efforts in helping students cope with trauma-related issues. Indeed, teachers themselves may be struggling with traumatic stress and loss that may affect their ability and willingness to participate in postdisaster interventions with students (Wolmer et al., 2003). Teachers who have severe reactions and personal losses may feel unable or unwilling to participate in postterrorism psychosocial interventions with their students (Wolmer et al., 2003). It is also plausible that teachers who experience personal distress in reaction to terrorist events may feel greater concern for the psychological impact of terrorism on children, and thus may be more interested and active in conducting intervention activities.

\section{Current Study}

The current study examined experiences of teachers and nonteaching school personnel who were working in schools near Washington, D.C., at the time of the September 11, 2001, terror attack on the Pentagon. The D.C.-area was also plagued by sniper shootings shortly prior to data collection for this study. The sniper attacks took place during September and October 2002 in the D.C. metropolitan area. Eleven people were killed and three others critically injured in various locations throughout D.C., Maryland, and Virginia. Although schools were not directly targeted (one sniper shooting incident occurred outside of a school), they were certainly affected. The schools in the area were often on lockdown as a result of the sniper scares (Sedam \& Ford, 2007). Consequently, questions assessing exposure to the shootings were also included. These data were gathered approximately 18 months after the September 11, 2001, attacks and thus provide a retrospective view of the initial response to this tragedy and the period of adjustment that followed.

Our objectives were twofold: The first was to gauge the psychosocial adjustment of teachers and nonteaching school personnel related to the terrorist attacks on multiple dimensions, including trauma exposure, PTSS, posttraumatic growth, professional role performance, and use of mental health services. The second was to examine how their adjustment related to their interest and involvement in school-based psychosocial interventions to address students' terrorism-related concerns, such as holding class discussions, providing information, and communicating with parents. We expected that 
psychosocial adjustment would be related to teachers' and nonteaching school personnel's interest and involvement in terrorism-related interventions for students, but given the dearth of prior research on this topic, we did not generate directional hypotheses. In addition to their own psychosocial adjustment, we assessed how perception of students' needs and involvement in intervening affected interest in information on psychosocial interventions following terrorism. We also explored the factors related to actual involvement in interventions following the terror events that affected this community.

\section{Methods}

\section{Participants}

Participants included 399 teachers and nonteaching school personnel of a Washington, D.C.-area school district who worked in a school during the 2001-2002 academic year. The sample consisted of 331 teachers, 32 other professionals (e.g., school psychologists, speech therapists), 20 general office employees, and 16 administrators (e.g., principals, vice principals). Participants had an average age of 43.3 years and were predominantly female (85\%) and White (83\%; 9\% Black; 6\% Hispanic). Participants worked in their current positions an average of 7 years (range $=1-35$ years). This sample represents $17 \%$ and $23 \%$ of nonteaching and teaching employees, respectively.

\section{Procedures}

Participants were surveyed from February through March 2003 regarding the September 11, 2001, terrorist attacks and the fall 2002 sniper attacks. With school district and institutional review board (IRB) approval for the research, surveys were distributed through the Employee Assistance Program (EAP) to all schools within the district. Some schools distributed surveys in staff meetings and asked that they be completed there; other schools put the questionnaires in staff mailboxes with a deadline for completion. The EAP encouraged participation of all of the approximately 1,800 school-based personnel through its ongoing relationship with principals and staff and through wellness coordinators at each site. Participants received an introduction letter describing informed consent, with consent assumed if they completed and returned the questionnaire.

\section{Measures}

The comprehensive survey used in this study was adapted from instruments used in prior research, including a study of teachers after the 1995 Oklahoma City bombing (B. Pfefferbaum et al., 2004) and a pilot study of teachers in a New York City school after the September 11, 2001 attacks (R. Pfefferbaum et al., 2004). The survey, which focused primarily on the September 11, 2001, attacks, covered exposure, peritraumatic reactions, and posttraumatic stress and depressive symptoms as well as issues related to professional roles, preparedness, and posttraumatic growth. As participants also lived in an area affected directly by the D.C.-area sniper attacks in the fall of 2002, additional items were added to gauge exposure to these attacks. Different versions of the survey addressed specific categories of personnel in the school district (including teachers, nonteaching professionals, administrators, and general office employees) with attention to their primary roles. The constructs and measures used in this study are described in the next section.

\section{Peritraumatic Event Variables}

The following are the peritraumatic event variables.

Exposure. Exposure to the terror events was measured with a series of 10 yes/no questions that were summed to represent the cumulative level of exposure to the attacks on the Pentagon and 
WTC and the 2002 sniper attacks. Items included proximity to terrorist events, witnessing events as they happened (in person, on live television), knowing someone killed or injured in the Pentagon, WTC, or sniper attacks, and knowing someone who knew someone who was killed or injured in any of these attacks.

Peritraumatic Distress. This was measured by asking participants if they reacted with intense fear, helplessness, or horror to both the WTC and Pentagon attacks when they first learned of the events. Participants answered "yes" or "no" for each of three items. Scores were summed with a possible range of $0-6$. The internal consistency was acceptable $(\alpha=.77)$.

\section{Psychosocial Adjustment}

The following address psychosocial adjustment.

PTSS. This measure was composed of 17 items drawn directly from the Diagnostic and Statistical Manual of Mental Disorders, Fourth Edition, Text Revision (American Psychiatric Association; 2000) symptom criteria for PTSD, where higher scores indicated more symptoms. The items asked for symptoms related to September 11, 2001, during the month prior to the survey. Response options were on a 5-point scale ("not at all" to "always"). We report scores for the three symptom clusters of PTSD: Intrusive Re-experiencing, Avoidance, Hyperarousal ( $\alpha=.83$ for each of the three scales). This measure was not used to diagnose PTSD, but rather to gauge recent symptoms of posttraumatic stress related to the terrorist attacks.

Depressive Symptoms. This composite score of three items represents symptoms of depression that participants reported (e.g., feeling hopeless). A 5-point scale ("not at all" to "always"; $\alpha=.88$ ) was used to measure frequency of symptoms. Participants were asked to indicate the extent to which they experienced symptoms in the past month compared to before September 11, 2001.

Difficulty in School Role Performance. Across three items, participants rated the extent to which the September 11, 2001, attacks made it difficult to perform work duties (e.g., "do your job") in the past month compared to prior to the attacks, using a 4-point scale ("not at all" to "a lot"). Higher scores indicated greater difficulty in school role performance $(\alpha=.92)$.

Work Responsibilities. This single item asked participants how they managed their work responsibilities in the first week post-September 11, 2001, using a 4-point scale ("with no added difficulty" to "with extreme difficulty").

Professional Role. This single item assessed participants' comfort with their professional role on September 11, 2001. Response options were on a 5-point scale ("very comfortable" to "not at all comfortable").

Behavior Change. This set of five items assessed whether participants perceived changes in their behavior and attitudes related to terrorism since September 11, 2001 (e.g., "You avoid public events or crowded areas more"). Response options were on a 4-point scale ("strongly disagree" to "strongly agree"). Internal consistency estimates indicate acceptable reliability ( $\alpha=.77)$.

Posttraumatic Growth. The 10 items assessing the degree to which participants experienced positive change as a result of the September 11, 2001, attacks were adapted from the Posttraumatic Growth Inventory (Tedeschi \& Calhoun, 1996; e.g., "You have changed your priorities about what is important in life"). Participants responded on a 4-point scale ("not at all" to "a lot"; $\alpha=.92$ ). 
Preparedness and Recovery Efforts

These variables are described below.

Preparedness. Participants rated their preparedness to handle student problems related to traumatic events before, during, and in the first few weeks after the September 11, 2001, attacks. These three items were on a 4-point scale ("not at all prepared" to "fully prepared"; $\alpha=.84$ ).

Change in Student Adjustment Problems. Participants were asked to rate how the frequency of each of eight problematic behaviors and feelings exhibited by students (e.g., "disputes or arguments between students," "nervousness or tension in students") changed since the September 11, 2001, attacks occurred. Change was reported on a 5-point scale ("decreased markedly" to "increased markedly"; $\alpha=.83$ ).

Interest in Psychosocial Interventions for Terrorism. Nine items assessed participants' interest in obtaining more information or training addressing terrorism-related topics at school (see Table 2). Items were rated on a 4-point scale ("strongly disagree" to "strongly agree"; $\alpha=.94$ ).

Involvement in Terrorism-Related Psychosocial Interventions for Children. Participants indicated how often they had engaged in each of five types of psychosocial interventions related to the September 11, 2001, attacks during the school year in which the attacks occurred (see Table 4), using a 5-point scale ("not at all" to "very often"; $\alpha=.78$ ).

\section{Data Analysis}

Descriptive statistics and zero-order correlations were used to describe participants' peritraumatic experiences, psychosocial adjustment, and involvement with students following the repeat terror events that occurred and to document interrelationships among study variables (see Table 1). We used hierarchical multiple regression to assess how individual factors and aspects of the recovery environment were related to interest in psychosocial interventions for terrorism. In the first step, we entered exposure and peritraumatic distress. In the second step, we added participants' psychosocial reactions in terms of PTSS clusters, behavior change, impairment in role performance, posttraumatic growth, and depressive symptoms. These were added at the second step to control for the influence of peritraumatic distress. In the final step, we added factors related to perception of the school environment that may affect interest in information on psychosocial interventions for terrorism (such as perceiving increased student problems) and how often participants intervened with students. We added the later to take into account how emotional reactions may influence perception of the school environment.

We also used multiple regression to assess how feeling prepared to handle work responsibilities on, or in the first week after, September 11, 2001; exposure; peritraumatic distress; and perceiving increased student problems following the terror events were related to frequency of interventions following the terror events. Variables were entered simultaneously.

\section{RESULTS}

\section{Psychosocial Adjustment of School Personnel}

Trauma Exposure. Thirty respondents witnessed the September 11, 2001, Pentagon attack in person, and six reported witnessing the WTC attack in person, together representing $9 \%$ of the sample. An additional $25 \%$ and $40 \%$ saw the Pentagon and WTC attacks live on television as they occurred, respectively. Almost $30 \%$ of respondents reported that they personally knew someone killed, injured, or missing in one of the September 11, 2001, terrorist attacks, and 79\% reported 


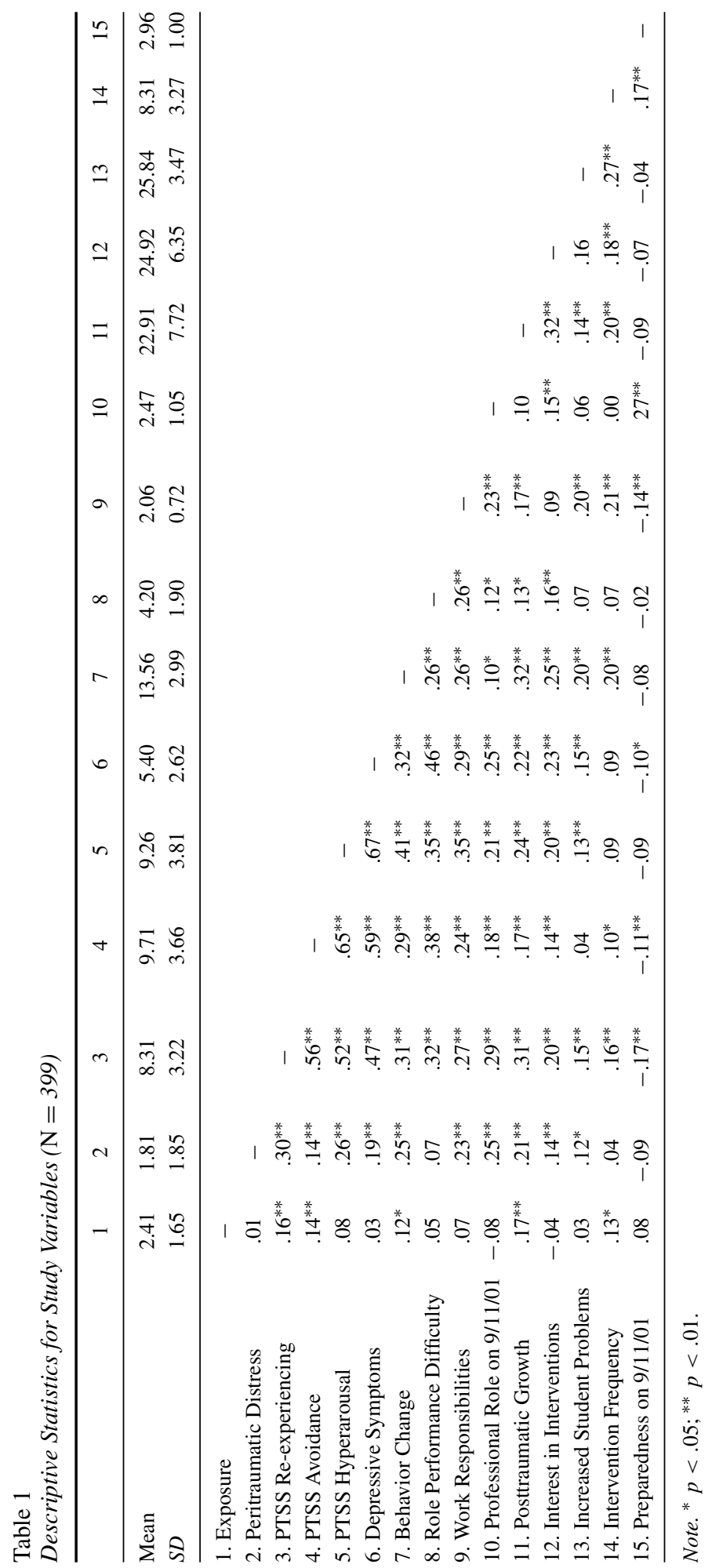

Psychology in the Schools DOI: 10.1002/pits 
knowing someone who knew someone who was killed, injured, or missing in those attacks. Although this is not an indicator of direct exposure, it provides qualitative information about the emotional recovery environment. For the sniper shootings, three respondents knew someone personally who was killed or injured, and $20 \%$ knew someone who knew a person who was killed or injured by the sniper. Overall, $63 \%$ of participants reported responding with intense fear, horror, or helplessness to the September 11, 2001, terrorist attacks.

Posttraumatic Stress and Growth. Nearly $12 \%$ of respondents reported that, in the past month, they "often" or "always" experienced one or more symptoms of intrusive re-experiencing, 27\% experienced at least one symptom of hyperarousal, almost $10 \%$ experienced an avoidance or numbing symptom, and $11 \%$ experienced one or more depressive symptoms. A similar proportion (45\%) reported that they experienced a lot of change on at least one item indicating posttraumatic growth. Peritraumatic distress generally had a stronger relationship to psychosocial adjustment than exposure did.

Role Performance. Only 5\% felt that the September 11, 2001, attacks caused "a lot" of difficulty for them in one or more aspects of their work performance in the previous month, although $15 \%$ reported "some" difficulty. In addition, nearly one half $(44 \%)$ "strongly agreed" that their behavior and attitudes associated with terrorism had changed in one or more ways since September $11,2001$.

Service Use. Approximately 9\% of respondents reported receiving mental health counseling before the September 11, 2001, terrorist attacks, and 5\% reported seeking help from a mental health professional since the attacks. Using $t$ tests, there was no significant difference on any of the indicators of psychosocial adjustment between those who received prior mental health counseling and those who did not.

\section{Influence of Adjustment on Interest and Involvement in Psychosocial Interventions}

Descriptive Information on Preparedness and Recovery Efforts. Most participants (68\%) reported feeling "unprepared" or "barely prepared" to handle student problems related to traumatic events prior to September 11, 2001. More felt prepared during the first few weeks after the attacks, although one-half continued to feel "barely prepared" or less. By the time of this survey, 18 months later, most felt "prepared" (52\%) or "fully prepared" (6\%).

Most participants reported interest in learning about terrorism-related preparedness and postevent intervention (Table 2). The top three areas of interest were dealing with students' emotional reactions, building resilience in students, and identifying children with emotional reactions. Participants were relatively less interested in information on how to balance their personal priorities with students' needs and how to handle their own reactions.

Factors Influencing Interest and Involvement in Psychosocial Interventions. Table 3 displays our model assessing interest in psychosocial interventions for terrorism, $F(12,369)=5.41, p<$ .001). Results revealed that, on the first step, peritraumatic distress was significantly related to interest but exposure was not. Step 2 assessed whether psychosocial adjustment was related to interest in interventions, controlling for peritraumatic events. The psychosocial variables accounted for an additional $12 \%$ of the variance when entered as a set in Step 2. Approximately half of this increment in $R^{2}$ was explained by variance shared among the psychosocial variables included in Step 2. A statistically significant unique effect was observed for posttraumatic growth. Step 3 assessed whether two variables in the school environment (perceived change in student adjustment problems, involvement in providing terror-related interventions) were related to interest in learning 
Table 2

Teacher and Nonteaching Personnel's Reports of Information They Would Like to Receive Related to Terrorism $(\mathrm{N}=399)$

\begin{tabular}{lc}
\hline Item & $\%$ Agree* \\
\hline Dealing with students' emotional reactions & $80 \%$ \\
Building resilience in students & $76 \%$ \\
Identifying children with emotional reactions & $75 \%$ \\
Knowing what to tell students about terrorist activities & $73 \%$ \\
Resolving ethical dilemmas & $65 \%$ \\
Communicating information about activities, discussions, and reactions to parents & $65 \%$ \\
Deciding how much school time to give to topics associated with terrorism & $60 \%$ \\
Knowing how to balance my own personal priorities with student needs & $57 \%$ \\
Identifying my own reactions to an event and the implications for students & $56 \%$ \\
\hline
\end{tabular}

Note. * Represents the sum of "Agree" and "Strongly Agree."

more about addressing terrorism-related topics, controlling for peritraumatic events and psychosocial adjustment. These variables entered as a set did not account for a statistically significant change in $R^{2}$.

As school personnel are on the front lines of helping children recover over the long term after a crisis, we explored the types of interventions that teachers and nonteaching personnel used with students. In Table 4, we display the results for teachers, nonteaching personnel, and the combined sample. Nonteaching personnel were more likely than teachers to report counseling students, $\mathrm{X}^{2}$ $(1,395)=6.36, p<.01$, referring students to a mental health professional, $X^{2}(1,394)=7.90$,

Table 3

Summary of Hierarchical Regression Predicting Interest in Information on Psychosocial Interventions for Terrorism $(\mathrm{N}=384)$

\begin{tabular}{|c|c|c|c|c|c|c|}
\hline \multirow[b]{2}{*}{ Predictor } & \multicolumn{3}{|c|}{ Set Statistics } & \multicolumn{3}{|c|}{ Decomposition of Set Effects } \\
\hline & $\Delta R^{2}$ & $R^{2}$ & $F$ change & B & $S E \mathrm{~B}$ & B \\
\hline Step 1: Peritraumatic Event Variables & $.02 *$ & .02 & $4.30^{*}$ & & & \\
\hline Exposure & & & & -.19 & .19 & -.05 \\
\hline Peritraumatic Distress & & & & .49 & .18 & $.14^{* *}$ \\
\hline Step 2: Psychosocial Adjustment & $.12^{* *}$ & .14 & $7.40^{* *}$ & & & \\
\hline PTSS Intrusive Re-experiencing & & & & .10 & .12 & .05 \\
\hline PTSS Avoidance & & & & -.06 & .12 & -.03 \\
\hline PTSS Hyperarousal & & & & .01 & .13 & .00 \\
\hline Behavior Change & & & & .24 & .12 & .11 \\
\hline Depressive Symptoms & & & & .21 & .17 & .09 \\
\hline Posttraumatic Growth & & & & .20 & .04 & $.24^{* *}$ \\
\hline Difficulty in School Role Performance & & & & .25 & .18 & .08 \\
\hline Step 3: School & .01 & .15 & 2.40 & & & \\
\hline Increased Student Problems & & & & .07 & .09 & .04 \\
\hline Involvement in Interventions & & & & .18 & .10 & .09 \\
\hline
\end{tabular}

Note. SE: standard error. ${ }^{*} p<.05$; $^{* *} p<.01$.

Psychology in the Schools $\quad$ DOI: 10.1002/pits 
Table 4

Frequency of Involvement in Interventions with Students for Teachers and Nonteaching Personnel

\begin{tabular}{|c|c|c|c|c|c|c|}
\hline \multirow[b]{2}{*}{ Intervention } & \multicolumn{2}{|c|}{ Teacher } & \multicolumn{2}{|c|}{ Nonteaching Personnel } & \multicolumn{2}{|c|}{ Total } \\
\hline & $N$ & $\%$ & $N$ & $\%$ & $N$ & $\%$ \\
\hline Counseled one on one & 330 & $34 \%$ & 65 & $51 \%$ & 395 & $37 \%$ \\
\hline $\begin{array}{l}\text { Referred to a school psychologist or other } \\
\text { mental health professional }\end{array}$ & 329 & $30 \%$ & 65 & $48 \%$ & 394 & $33 \%$ \\
\hline Contacted parent(s) about child's reaction & 329 & $17 \%$ & 64 & $34 \%$ & 393 & $20 \%$ \\
\hline Held class discussions & 330 & $61 \%$ & 64 & $44 \%$ & 394 & $58 \%$ \\
\hline
\end{tabular}

Note. Data represent the percentage of respondents who responded "Sometimes" or more frequently.

$p<.01)$, and contacting parents about a child's reaction, $\mathrm{X}^{2}(1,393)=10.60, p<.01$. When exploring who among the group of nonteaching personnel engaged in these efforts, it was principals, vice principals, school counselors, and school psychologists, not other professionals or support staff. Not surprisingly, teachers were more likely than nonteaching personnel to report holding class discussions about the events, $\left.\mathrm{X}^{2}(1,394)=6.25, p<.05\right)$.

Using multiple regression, we then tested a model of how feelings of preparedness to handle work responsibilities on, or in the first week after, September 11, 2001, exposure, peritraumatic distress, and perceiving increased student problems were related to actual involvement in psychosocial interventions for terrorism (see Table 5 for results). The model indicated that participants' feelings of preparedness to handle students before September 11, 2001, their ability to adaptively manage work responsibilities in the first week after the attacks, and their perception that student problems increased since the attacks were significantly related to their involvement in psychosocial interventions with students, $F(6,373)=10.42, p<.01$.

\section{DISCUSSION}

Residents of the Washington, D.C., area coped with several traumatic experiences in the 18 months prior to this study, including the September 11,2001, terrorist attacks and sniper shootings. In these types of situations, teachers may be asked to move beyond their educational responsibilities to be aware of and perhaps directly address the emotional needs of students (B. Pfefferbaum et al.,

Table 5

Summary of Regression Predicting Involvement in Psychosocial Interventions $(\mathrm{N}=379)$

\begin{tabular}{lccc}
\hline Decomposition of Set Effects & B & $S E$ B & $\beta$ \\
\hline Before 9/11/01, how prepared did you feel to handle student problems? & .62 & .16 & $.19^{* *}$ \\
Work Responsibilities & .85 & .23 & $.19^{* *}$ \\
Professional Role & .04 & .16 & .01 \\
Peritraumatic Distress & -.03 & .09 & -.02 \\
Exposure & .19 & .10 & $.09^{*}$ \\
Increased Student Problems & .23 & .05 & $.23^{* *}$ \\
\hline Set Statistics & $R^{2}=.14$ & \\
& $F(6,373)=10.42, p<.01$ \\
\hline
\end{tabular}

Note. SE: standard error. ${ }^{*} p=.051 ;{ }^{* *} p<.01$. 
2004). In this study, we considered the perspective of teachers and nonteaching personnel as they coped with their own emotional reactions to the traumatic events and helped their students. We assessed their exposure to the traumatic events, psychosocial adjustment, interest in postevent interventions, and factors that influenced their involvement in interventions with students. This study, although it is a retrospective study using a convenience sample, suggests that the unique perspective of teachers and nonteaching personnel should be included in research on how school systems cope with trauma. This will help guide school administrators, practitioners, policy makers, and researchers when they develop, implement, and evaluate efforts to improve the crisis preparedness of schools.

\section{Psychosocial Adjustment of School Personnel}

We found that the amount of exposure varied more than peritraumatic distress. Although the majority of the sample did not observe the September 11, 2001, attacks or sniper events as they occurred, 63\% reported reacting with fear, helplessness, and horror. This finding lends support to research suggesting that indirect exposure to large-scale traumatic events may be important to assess. Exposure and peritraumatic distress were not related to each other in this sample, but both were related to psychosocial adjustment. Peritraumatic distress was more strongly related to adjustment than was exposure, which is consistent with views that initial cognitive and emotional appraisals of traumatic events play an important role in shaping the impact of terrorism events on subsequent psychosocial adjustment (Bryant, Salmon, Sinclair, \& Davidson, 2007).

Although surveyed almost 18 months after the September 11, 2001, terrorist attacks, participants continued to report experiencing some psychological symptoms that they related to the attacks. In the month prior to the survey, between $10 \%$ and $27 \%$ continued to report at least one symptom of posttraumatic stress (depending on PTSD symptom category), $11 \%$ at least one symptom of depression, and nearly one-half reported that their behavior or attitudes about terrorism changed and/or they reported one or more experiences of posttraumatic growth. When students, teachers, and staff are affected by the same traumatic events, psychosocial preparedness and recovery must be considered for each (Greene et al., 2004). It is worth noting that participants in our study reported relatively less interest in training about self-care issues than in how to assist students in recovery. Despite acknowledging ongoing personal repercussions, few school personnel had sought mental health services to address their own reactions to the terrorist attacks. Further research is needed to determine whether self-care information or other strategies to offer mental health services for school personnel might facilitate their personal recovery and subsequent ability to aid students.

\section{Interest and Involvement in Psychosocial Interventions}

Although schools are charged with preparing for crises, the quality of their plans varies; there may be gaps in coordination with public health, mental health, and other emergency responders; and more training is needed across all levels of staff (Greene et al., 2004; Olympia, Wan, \& Avner, 2005; Sapien \& Allen, 2001). Many have called for schools to be more prepared for crises, but few published studies have empirically examined preparedness and the factors that affect it. Most research in this area has involved surveys of members of professional associations, such as school nurses (e.g., Olympia et al., 2005) and school psychologists (e.g., Nickerson \& Zhe, 2004). Greene and colleagues (2004) recommend research on the issues affecting the ability of schools to respond to terrorism, and we begin to fill this gap. Our study adds the voice of teachers and nonteaching personnel about the types of preparedness training they would like. Overwhelmingly, they wanted to know how to identify and deal with the psychological and emotional aftermath of a traumatic event on students and were relatively less concerned about their own reactions and needs. This finding 
suggests that mental health trainings designed for delivery by non-mental health professionals might be welcomed by many teachers.

Interest in Interventions. We explored the factors related to interest in psychosocial interventions for dealing with the aftermath of terrorism. We tested a model that hypothesized that exposure, peritraumatic distress, psychosocial adjustment, and perceptions that students' problems increased would affect interest in psychosocial intervention-training activities. Greater peritraumatic distress was related to greater interest in learning about psychosocial interventions for students. Similarly, participants who reported greater long-term psychosocial impact of the terror events indicated greater interest in learning more about interventions for students. Interestingly, posttraumatic growth, the sole psychosocial adjustment measure that was not oriented toward symptoms of distress, had the strongest relationship with interest in gaining more training. Changes in self, sense of relationships with others, and philosophy of life have all been linked to posttraumatic growth (Tedeschi \& Calhoun, 1996), and that may be what motivated participants with higher posttraumatic growth to become interested in interventions for students. Future studies should attempt to replicate these findings with representative samples of teachers with various levels of exposure to traumatic events.

We assessed whether perceiving increased student problems as a result of the traumatic events and frequency of involvement in intervening with students was related to interest in psychosocial interventions. We did find these relationships at the level of zero-order correlations, but these did not hold up when we controlled for peritraumatic events and psychosocial adjustment. It is possible that respondents had a difficult time determining if student behavior changed as a result of the attacks, in part, because the attacks occurred at the beginning of the school year. Indeed, many were mixed on whether problems increased. This finding is consistent with research on the Oklahoma City bombing, even though that event occurred toward the end of the school year (B. Pfefferbaum et al., 1999). In this latter case, there may not have been enough time after the event for teachers to feel confident in their assessment of student needs. Other research suggests that there may be a delayed effect for social and emotional problems (Smilde-van den Doel, Smit, \& Wolleswinkel-van den Bosch, 2006). Also, teachers are not typically trained to detect trauma-related emotional or behavioral concerns.

Intervening with Students. In addition to playing a central role in crisis response to terrorist events, schools are potentially important agents in the recovery process. As noted by Greene and colleagues (2004), schools are (a) places where large numbers of children gather on a daily basis; (b) en loco parentis; (c) resources for the community; (d) places of learning that can use their educational mission to teach children skills to prepare, stay safe, and cope; and (e) places of health care delivery where recovery services also can be delivered. They argue that schools can efficiently deliver services that provide normalization to children, reach underserved youth, and provide peer and adult support.

School and class response may not be uniform, however, in the immediate aftermath (B. Pfefferbaum et al., 2003). In the school district we studied, the interventions preferred by teachers and nonteaching personnel differed based on role. Teachers were most likely to report holding class discussions, but the content of the discussions and the effect discussions had on students is unknown. Teachers were less likely to report contacting parents or counseling a student individually. Nonteaching personnel, such as principals, vice principals, school counselors, and psychologists, were more likely to report counseling and referral to a mental health professional, perhaps because they are more likely to have specific training in this than are teachers. If teachers were trained to identify mental health reactions in their students and were given appropriate referral resources, they might become more involved in counseling and referrals. 
We explored the factors that may influence the frequency with which teachers and nonteaching personnel actually intervened with students about the terrorist attacks. Feeling prepared before the terrorist attacks, the ability to adaptively manage work responsibilities in the immediate aftermath, and perceiving increased student problems were significantly related to intervening with students. Feeling prepared and able to manage work responsibilities may be linked to individual self-efficacy, and future research should explore this. The ability of teachers and school staff to effectively help students could be improved by training in preparedness, management, and recovery before a crisis event occurs. Training and supervision that helps teachers and nonteaching personnel recognize and be sensitive to emotional reactions in students can also influence their perceptions of a need to intervene. Clinicians, school administrators, and researchers need to be aware of and address these possible training needs when implementing school-based interventions to promote adaptive recovery from trauma.

\section{Implications for Practice}

Schools consider the scope and severity of the event, resilience of the population, resources available, and readiness of the system when deciding the most appropriate interventions after a traumatizing event (Wolmer et al., 2003). Greene and colleagues (2004) list numerous federal, national professional association, and nonprofit resources that schools can use in disaster preparedness, response, and recovery. For dealing with the mental health impact of traumatizing events, there are several additional resources. For example, the National Child Traumatic Stress Network and National Center for PTSD have jointly developed a Psychological First Aid protocol (Brymer et al., 2006). Another Psychological First Aid series, Listen, Protect, and Connect, has been developed specifically for teachers (Schreiber, Gurwitch, \& Wong, 2006). The National Association of School Psychologists offers the PREPaRE curriculum that schools can use to prepare for emergencies (Brock et al., 2009). Finally, Henley (2005) describes a resilience-focused play and recreation intervention that is potentially adaptable for teachers and the school environment. Used appropriately, these resources could positively influence the recovery trajectory of students, teachers, and other school personnel.

\section{Strengths and Limitations}

This study provided the unique perspective of teachers and nonteaching personnel within schools on how terrorism continues to affect them, how prepared they feel for crises, and the factors that influence their interest and frequency in intervening with students. This knowledge is crucial for best using school-based human resources to build sustainable and effective response and recovery programs for students. The findings must be interpreted in light of the fact that this is a crosssectional, retrospective, self-report study of a convenience sample. Participants were asked to recall their reactions surrounding the September 11, 2001, attacks and compare them to the month prior to the survey. As traumatic events can create vivid memories, retrospective recall may be better for the content of this study, compared with retrospective studies of ordinary events. Ideally, however, longitudinal data would be collected at various times in the recovery process, starting soon after the event, to understand how reactions change. Although the survey was piloted in a prior study, many measures were not standardized instruments with established psychometrics. In addition, separate questions about the effects of the sniper attacks on psychosocial adjustment, compared to the September 11, 2001, terror attacks, were not included. This study begins, however, to address an important gap in school-based research on disaster preparedness and recovery and can be used as a building block for future studies. 


\section{REFERENCES}

Adams, R. E., \& Boscarino, J. A. (2005). Stress and well-being in the aftermath of the world trade center attack: The continuing effects of a communitywide disaster. Journal of Community Psychology, 33(2), 175-190. doi: 10.1002/jcop.20030.

American Psychiatric Association. (2000). Diagnostic and statistical manual of mental disorders (4th ed., text revision). Washington, DC: American Psychiatric Association.

Benight, C. C., \& Bandura, A. (2004). Social cognitive theory of posttraumatic recovery: The role of perceived self-efficacy. Behaviour Research and Therapy, 42, 1129-1148. doi: 10.1016/j.brat.2003.08.008.

Brock, S. E., Nickerson, A. B., Jimerson, S. R., Reeves, M. A., Lieverman, R. A. \& Feinberg, T. A. (2009). School crisis prevention and intervention: The PREPaRE model. Bethesda, MD: National Association of School Psychologists.

Bryant, R. A., Salmon, K., Sinclair, E., \& Davidson, P. (2007). A prospective study of appraisals in childhood posttraumatic stress disorder. Behaviour Research and Therapy, 45(10), 2502-2507. doi: 10.1016/j.brat.2007.04.009.

Brymer, M., Layne, C., Jacobs, A., Pynoos, R., Ruzek, J., Steinberg, A., et al. (2006) Psychological first aid field operations guide (2nd ed.). Los Angeles, CA: National Child Traumatic Stress Network and National Center for PTSD. Retrieved April 17, 2006, from www.nctsn.org and www.ncptsd.va.gov.

Galea, S., Ahern, J., Resnick, H., Kilpatrick, D., Bucuvalas, M., Gold, J., et al. (2002). Psychological sequelae of the September 11 terrorist attacks in New York City. New England Journal of Medicine, 346(13), 982-987.

Greene, B., Barrios, L. C., Blair, J. E., \& Kolbe, L. (2004). Schools and terrorism: A supplement to the Report of the National Advisory Committee on Children and Terrorism. Journal of School Health, 74, 39-51.

Henley, R. (2005). Helping children overcome disaster trauma through post-emergency psychosocial sports programs. Retrieved March 2, 2007, from http://ni.floor.ch/data/sad/content/document/493.pdf

Mearns, J., \& Cain, J. E. (2003). Relationships between teachers' occupational stress and their burnout and distress: Roles of coping and negative mood regulation expectancies. Anxiety, Stress \& Coping: An International Journal, 16(1), $71-82$. doi: 10.1080/1061580021000057040.

Nickerson, A. B., \& Zhe, E. J. (2004). Crisis prevention and intervention: A survey of school psychologists. Psychology in the Schools, 41, 777-788. doi: 10.1002/pits.20017.

Norris, F. H., Friedman, M. J., Watson, P. J., \& Byrne, C. M. (2002). 60,000 disaster victims speak: Part 1. An empirical review of the empirical literature, 1981-2001. Psychiatry, 65(3), 207-239. doi: 10.1521/psyc.65.3.207.20173.

Olympia, R. P., Wan, E., \& Avner, J. R. (2005). The preparedness of schools to respond to emergencies in children: A national survey of school nurses. Pediatrics, 116(6), e738-e745.

Pfefferbaum, B., Nixon, S. J., Krug, R. S., Tivis, R. D., Moore, V. L., Brown, J. M., et al. (1999). Clinical needs assessment of middle and high school students following the 1995 Oklahoma City bombing. American Journal of Psychiatry, 156, $1069-1074$.

Pfefferbaum, B., Pfefferbaum, R. L., Gurwitch, R., Doughty, D. E., Pynoos, R. S., Foy, D. W., et al. (2004). Teachers' psychological reactions 7 weeks after the 1995 Oklahoma City bombing. American Journal of Orthopsychiatry, 74, $263-271$.

Pfefferbaum, B., Sconzo, G. M., Flynn, B. W., Kearns, L. J., Doughty, D. E., Gurwitch, R. H., et al. (2003). Case finding and mental health services for children in the aftermath of the Oklahoma City bombing. Journal of Behavioral Health Services \& Research, 30, 215-227. doi: 10.1007/BF02289809.

Pfefferbaum, R. L., Fairbrother, G., Brandt, E., Robertson, M. J., Gurwitch, R. H., Stuber, J., et al. (2004). Teachers in the aftermath of terrorism: A case study of one New York City school. Family and Community Health, 27, 250-259.

Sapien, R. E., \& Allen, A. (2001). Emergency preparation in schools: A snapshot of a rural state. Pediatric Emergency Care, $17,329-333$.

Schreiber, M., Gurwitch, R., \& Wong, M. (2006). Listen protect, and connect-Model \& teach: Psychological first aid for children. Retrieved April 24, 2008, from www.ready.gov/kids/_downloads/PFA_SchoolCrisis.pdf.

Sedam, S. R., \& Ford, C. B. (2007). The days of living under the gun. Retrieved on February 20, 2008, from http://www.gazette.net/stories/100307/montnew94440_23266.shtml.

Silverman, W. K., \& La Greca, A. M. (2002). Children experiencing disasters: definitions, reactions, and predictions of outcomes. In A. M. La Greca, W. K. Silverman, E. M. Vernberg, \& M. C. Roberts (Eds.), Helping children cope with disasters and terrorism. (pp. 11-33). Washington, DC: American Psychological Association. 10.1037/10454-001.

Smilde-van den Doel, D. A., Smit, C., \& Wolleswinkel-van den Bosch, J. H. (2006). School performance and social-emotional behavior of primary school children before and after a disaster. Pediatrics, 118(5), e1311-e1320.

Tedeschi, R. G., \& Calhoun, L. G. (1996). The posttraumatic growth inventory: Measuring the positive legacy of trauma. Journal of Traumatic Stress, 9, 455-471. doi: 10.1002/jts.2490090305.

Wolmer, L., Laor, N., Dedeoglu, C., Siev, J., \& Yazgan, Y. (2005). Teacher-mediated intervention after disaster: A controlled three-year follow-up of children's functioning. Journal of Child Psychology and Psychiatry, 46, 1161-1168. doi: 10.1111/j.1469-7610.2005.00416.

Wolmer, L., Laor, N., \& Yazgan, Y. (2003). School reactivation programs after disaster: Could teachers serve as clinical mediators? Child and Adolescent Psychiatric Clinics of North America, 12, 363-381. doi: 10.1016/S1056-4993(02)00104-9. 